\title{
Diagnosis in the Neuroleptic Malignant Syndrome
}

James H. Dallman, MD, CPT, MC

Letterman Army Medical Center, San Francisco California

Follow this and additional works at: https://jdc.jefferson.edu/jeffjpsychiatry

Part of the Psychiatry Commons

Let us know how access to this document benefits you

\section{Recommended Citation}

Dallman, MD, CPT, MC, James H. (1986) "Diagnosis in the Neuroleptic Malignant Syndrome," Jefferson Journal of Psychiatry. Vol. 4 : Iss. 1 , Article 10.

DOI: https://doi.org/10.29046/JJP.004.1.011

Available at: https://jdc.jefferson.edu/jeffjpsychiatry/vol4/iss1/10

This Article is brought to you for free and open access by the Jefferson Digital Commons. The Jefferson Digital Commons is a service of Thomas Jefferson University's Center for Teaching and Learning (CTL). The Commons is a showcase for Jefferson books and journals, peer-reviewed scholarly publications, unique historical collections from the University archives, and teaching tools. The Jefferson Digital Commons allows researchers and interested readers anywhere in the world to learn about and keep up to date with Jefferson scholarship. This article has been accepted for inclusion in Jefferson Journal of Psychiatry by an authorized administrator of the Jefferson Digital Commons. For more information, please contact: JeffersonDigitalCommons@jefferson.edu. 


\title{
Brief Clinical Reports
}

\section{Diagnosis in the Neuroleptic Malignant Syndrome}

\author{
James H. Dallman, M.D., C.P.T., M.C.
}

\section{INTRODUCTION}

Neuroleptic malignant syndrome (NMS) is an uncommon, potentially lethal complication of treatment with antipsychotic medication. First described in American journals by Delay and Deniker in 1968 (1), this syndrome has been reported for many years in the European and Japanese literature.

Neuroleptic malignant syndrome is characterized by fever, altered mental status, autonomic dysfunction, and generalized skeletal muscle rigidity. Its appearance usually follows use of high potency neuroleptics in therapeutic doses. In the American literature, most reported cases have resulted from use of haloperidol, fluphenazine, thiothixene or piperazine derivatives (2,3). Longacting depot fluphenazine has been particularly implicated $(4,5)$. One reported case has been attributed to thioridazine therapy (6), and another to tetrabenazine and alphamethyltyrosine therapy (3).

Features of NMS are also described following use of neuroleptics in conjunction with lithium salts and tricyclic antidepressants, and in sedative withdrawal syndromes $(7,8)$. While persons of all ages may be affected, nearly $75 \%$ are under age 40 , male-to-female ratio being $2: 1$ (5).

\section{CASE REPORT}

A 22-year-old housewife in her eighth month of pregnancy developed emotional lability which continued until the uneventful delivery of a healthy baby boy at term. Following discharge from the hospital, the patient did well until three weeks post-partum, when her husband noted that she was exhibiting strange behavior. She would cry unexplainably and speak repeatedly on religious themes. On several occasions, she made telephone calls to her friends stating that their parents had died. Her speech became increasingly incoherent and fragmented, with perseveration of ideas. She began to neglect her housework and personal hygiene, appearing self-absorbed. The patient was referred for psychiatric evaluation and admitted to a local hospital.

Dr. Dallman wrote this paper while a fourth-year resident at Letterman Army Medical Center, San Francisco, California. 
Shortly after admission, the patient demonstrated restlessness and psychomotor agitation warranting an intramuscular injection of haloperidol, $2.5 \mathrm{mg}$. Following administration of the medication, she exhibited robot-like movements, muscular rigidity, and oculogyric crisis. Also noted were hypokinesia, psychomotor retardation, drowsiness, and tongue protrusion. Treatment with haloperidol, $2 \mathrm{mg}$ daily, was continued. On the eighth hospital day, the patient became unresponsive and incontinent of urine and feces. By hospital day ten, she required continuous nursing care. Intravenous fluids were administered and haloperidol was discontinued. Within two days, the patient became more responsive and was able to recognize her spouse.

Twelve days after admission to her local hospital, the patient was transferred to our facility. Physical examination noted an indwelling urinary catheter, large blisters on both heels, a protruding tongue with hypersalivation, and athetoid movements of the upper extremities. The following day, the patient showed increasing agitation, and thiothixene, $40 \mathrm{mg}$ orally, was given. Within 24 hours, she was noted to be diaphoretic and tachycardic. All neuroleptic medications were discontinued, and in the ensuing four days she improved. On the ninth hospital day, because of her increasing paranoia and accompanying agitation, the patient was given a dose of haloperidol, $10 \mathrm{mg}$ intramuscularly. Within 24 hours, she developed extreme muscular rigidity, diaphoresis, tachycardia, and hypersalivation. Her mental status became increasingly stuporous and the following day she developed hyperthermia $\left(38.6^{\circ} \mathrm{C}, 101.5^{\circ} \mathrm{F}\right)$, which lasted for approximately two days. A slow recovery followed with the discontinuation of all neuroleptic medication. She was discharged after 16 days in the hospital with no persistent side-effects.

\section{CLINICAL CHARACTERISTICS}

Classically, NMS is characterized by the triad of muscular rigidity, hyperthermia, and altered consciousness (9). Recent descriptions also include autonomic dysfunction $(2,10)$. Symptoms usually begin soon after starting or increasing the dosage of neuroleptics. Onset of the syndrome may occur within hours, or may be delayed for several months following initial drug exposure. Some NMS patients have reported previous asymptomatic exposure to neuroleptics; in other cases neuroleptics have been restarted without recurrence of NMS after the acute syndrome is resolved (2).

It is not clear why such variations exist. Perhaps neuroleptics may be necessary but are not in themselves sufficient to induce the syndrome. Itoh (10) noted that physical exhaustion associated with dehydration was an underlying condition of NMS in all 14 patients studied, suggesting that dehydrated and debilitated states may at least predispose or contribute to onset of NMS. In our patient, the post-partum state was present.

Among the earliest signs of NMS are extrapyramidal rigidity and involuntary movements, sometimes accompanied by dysarthria and dysphagia. Hyper- 
thermia, appearing after the extrapyramidal signs, may reach $41^{\circ} \mathrm{C}\left(105^{\circ} \mathrm{F}\right)$, or may be only moderately elevated (2). Consciousness is altered and can appear as a dazed mutism (similar to catatonia) with subsequent progression to stupor, coma, and death (2).

Autonomic dysfunction includes pallor, diaphoresis, sialorrhea, blood pressure instability, tachycardia, pulmonary congestion, and tachypnea. In some cases, tachypneic hypoventilation from decreased chest wall compliance necessitates respiratory support. Dehydration is common and may progress to acute renal failure in the absence of myoglobinuria. Less frequent signs are oculogyric crisis, opisthotonus, seizures, chorea, Babinski signs, and trismus.

Symptoms usually resolve within five to ten days after stopping oral neuroleptics but last for several weeks after long-acting depot injections. In 16\% to $30 \%$ of cases fatalities have occurred from acute renal failure, respiratory failure, or cardiovascular collapse (2). Death has been more common among those who receive depot fluphenazine, probably because of its prolonged half-life. Postmortem examinations of the central nervous system have revealed no consistent abnormalities.

Laboratory findings frequently are normal. Transient elevation of serum aldolase or creatinine phosphokinase (CPK) has been repeatedly observed. Laboratory concomitants of dehydration can be seen, and liver parenchymal enzyme elevations have been noted. Leukocytosis with a polymorphonuclear cell predominance is common without other evidence of infection. The sedimentation rate may be elevated. Cerebrospinal fluid is normal, as is the computerized tomography scan. The electroencephalogram may be normal or nonspecifically slow, suggesting diffuse metabolic encephalopathy.

\section{DIFFERENTIAL DIAGNOSIS}

Hyperthermia and altered mental status are cardinal signs of CNS infections, therefore, NMS is most often mistaken for an infection. Bacterial, fungal and parasitic infections, viral or syphilitic encephalitis, and even tetanus must be ruled out in the differential diagnosis. Occasionally, trauma or neoplasms can produce akinetic mutism and hyperthermia of a central origin which also resembles NMS.

Drug allergy should be considered. One must look for eosinophilia and cutaneous abnormalities such as erythema or rash. Hypertonicity in NMS is similar to extrapyramidal rigidity and must be differentiated from basal ganglia diseases such as severe Parkinson's disease. Other disorders of muscle hypertonicity such as decerebrate and decorticate rigidity, tetany, and spasticity must be ruled out.

Catatonia may resemble NMS. The classic signs of catatonia, including catalepsy and waxy flexibility, negativism, mutism, muscular rigidity, and bizarre mannerisms can be present in NMS (11). Catatonia is a nonspecific descriptive syndrome which can result from metabolic, infectious, psychiatric, 
or structural brain disorders. In "lethal catatonia," sustained agitation progresses to withdrawal, stupor $(12,13)$, hypotension, hyperthermia, and death in days to weeks.

If the patient has been exposed to a hot environment, heat stroke should be considered, especially if anticholinergic drugs have been given as they can inhibit sweating. In heat stroke, as in NMS, hyperpyrexia and a depressed level of consciousness occur, but extrapyramidal signs prior to temperature elevation are lacking.

Finally, malignant hyperthermia (MH) must be considered in that hyperthermia, rigidity, and CPK elevation occur in both syndromes, and they may have a common pathophysiology $(2,12,14)$. In about one-third of the cases of $\mathrm{MH}$, predisposition is transmitted as an autosomal dominant trait; familial NMS has not been reported. Serum CPK, which is markedly elevated during MH, may also be increased in patients between attacks or among asymptomatic family members. Most patients with NMS have normal serum CPK before and after each episode. Mortality from MH approaches $70 \%$, whereas among cases of NMS it is less than $30 \%$.

\section{PATHOGENESIS}

The exact pathogenesis of NMS remains unclear. A popular hypothesis suggests a peripheral mechanism, mainly because of the clinical similarities between NMS and anesthetic-induced malignant hyperthermia (15). Studies have indicated that $\mathrm{MH}$ may result from excessive release of calcium into skeletal muscle cytoplasm due to altered membrane transport of calcium in the presence of certain drugs (15). Excess intracellular calcium could cause the rigidity and the subsequent hyperpyrexia seen in both MH and NMS.

Some authors $(2,12,16)$ have postulated that the disturbance of NMS is primarily central, suggesting that dopamine receptor blockade or dopamine depletion in the basal ganglia, hypothalamus, or brain stem is the main pathophysiologic mechanism. Impaired thermoregulation by neuroleptic drugs which block dopamine receptors, is seen both clinically and experimentally. Dopamine and related neurotransmitters are found in the hypothalamus, and dopamine receptors of the D-1 class, which mediate thermoregulation, are located in the preoptic anterior hypothalamus. The mesolimbic dopaminergic pathways may also play a role in thermoregulation.

Hyperpyrexia can result from elevation of the hypothalamic "set-point," impaired heat dissipation mechanisms, or excess heat production. Because patients with NMS sweat profusely, some peripheral routes of heat dissipation are intact. However, vasoconstriction is seen in neuroleptic-treated animals made hyperthermic, and pallor in NMS patients suggests that there is peripheral vasoconstriction which prevents heat transfer from the body core to the environment. A considerable amount of heat is generated by the profound rigidity and tremors seen in NMS. These extrapyramidal signs precede, and probably contribute to, the hyperpyrexia. 


\section{TREATMENT}

To achieve results in treating NMS, symptoms must be recognized early and all psychotropic medications must be promptly withdrawn. Until recently, medical treatment of NMS was limited to symptomatic therapy with intensive supportive medical care, with particular attention to maintenance of respiratory, renal, and cardiovascular systems. Vigorous treatment of hyperthermia as well as maintaining fluid and electrolyte balance has also been important.

Recent reports describe successful pharmacologic treatment of NMS using dantrolene sodium $(17,18,19)$. Dantrolene, a direct-acting skeletal muscle relaxant with unclear central effects, has been shown to be efficacious in treating malignant hyperthermia in animals and humans. In muscles, it dissociates excitation-contraction coupling by inhibiting the release of calcium ions from the sarcoplasmic reticulum (SR) through actions on the transverse tubular membrane-SR coupling, on SR directly, or both (20). Dosages of $50 \mathrm{mg}$ orally taken two to four times daily have resulted in rapid clinical improvement and shortened the duration of NMS from the usual five to ten days to less than three days. Further use of this agent in NMS patients is warranted to determine its efficacy, optimal dosage, and route of administration. Other pharmacologic therapies have been aimed at directly altering the CNS dopaminergic/cholinergic ratio through administration of anti-Parkinsonian agents. McCarron et al. (21) and Amdurski et al. (22) recently reported successfully treating NMS with amantadine. Bromocriptine has also been tried (23).

\section{SUMMARY}

Neuroleptic malignant syndrome is a rare but underrecognized complication of neuroleptic therapy characterized by generalized skeletal muscle rigidity, hyperthermia, autonomic dysfunction, and altered consciousness. Recognition of NMS and immediate withdrawal of neuroleptics usually leads to complete recovery. Failure to recognize this syndrome can increase the risk of morbidity and may lead to death in a significant percentage of patients. The pathogenesis of NMS remains unknown, but both peripheral and central mechanisms have been proposed. Based on these hypotheses, there have been reports of successful treatment using dantrolene sodium, a peripheral muscle relaxant and centrallyacting agents such as amantadine. Further studies are needed to elucidate the cause and optimal treatment of this syndrome.

\section{REFERENCES}

1. Delay J, Deniker P: Drug-induced extrapyramidal syndrome, in Handbook of Clinical Neurology: Diseases of Basal Ganglia. Edited by Vinken PJ, Bruyn GW. Amsterdam, North Holland Publishing Co: 248-266, 1968

2. Caroff SN: The neuroleptic malignant syndrome. J Clin Psych 41:79-83, 1980

3. Burke R, Fahn S, Mayeux R, et al: Neuroleptic malignant syndrome caused by 
dopamine-depleting drugs in a patient with Huntingdon disease. Neurology 31:10221026,1981

4. Grunhaus L, Sancovici S, Rimon R: Neuroleptic malignant syndrome due to depot fluphenazine. J Clin Psych 40:99-100, 1979

5. Meltzer HY: Rigidity, hyperpyrexia and coma following fluphenazine enanthate. Psychopharmacologia 29:337-346, 1973

6. Haberman ML: Malignant hyperthermia: an allergic reaction to thioridazine therapy. Arch Intern Med 139:800-801, 1978

7. Spring G, Frankel M: New data on lithium and haldol incompatibility. Am J Psych $138: 818-821,1981$

8. Baldessarini RJ, Lipinski JF: Toxicity and side effects of antipsychotic, antimanic, and antidepressant medication. Psych Annals 6:484-493, 1976

9. Morris HH 3d, McCormick WF, Reinarz JA: Neuroleptic malignant syndrome. Arch Neurol 37:462-463, 1980

10. Itoh H, Ohtsuka N, Ogita K, et al: Malignant neuroleptic syndrome-its present status in Japan clinical problems. Folia Psychiatr Neuro Jpn 31:565-576, 1977

11. Gelenberg A: The catatonic syndrome. Lancet 19:1339-1341, 1976

12. Henderson V, Wooten GF: Neuroleptic malignant syndrome: a pathogenic role for dopamine receptor blockade? Neurology 31:132, 1981

13. Stauder KH: Die tödliche katatonia. Arch Psychiatr Nervenkr 102:614-634, 1934

14. Lotstra F, Linkowski P, Mendlevicz J: General anesthesia after neuroleptic malignant syndrome. Biol Psychiatry 18:243-247, 1983

15. Gronert G: Malignant hyperthermia. Anesthesiology 53:395-423, 1980

16. Steele TE: Adverse reaction suggesting amoxapine-induced dopamine blockade. Am J Psych 139:1500-1501, 1982

17. Coons DJ, Hillman FJ, Marshall RW: Treatment of neuroleptic syndrome with dantrolene sodium: a case report. Am J Psychiatry 139:144-145, 1982

18. May DC, Morris SW, Steward RM, et al: Neuroleptic malignant syndrome: response to dantrolene sodium. Ann Int Med 98(2):183-184, 1983

19. Goulon M, DeRohan Chabot P, Elkharrot D: Beneficial effects of dantrolene in the treatment of neuroleptic malignant syndromes: a report of two cases. Neurology 33(4):516-518, 1983

20. Kolb ME, Horne ML, Martz R: Dantrolene in human malignant hyperthermia. Anesthesiology 56:254-262, 1982

21. McCarron M, Boettger M, Peck J: A case of neuroleptic malignant syndrome successfully treatment with amantadine. J Clin Psych 43(9):381-382, 1982

22. Amdurski S, Radwan M, Levi A, Elizin A: A therapeutic trial of amantadine in haloperidol induced malignant neuroleptic syndrome. Curr Ther Res Clin Ex 33(2):225-229, 1983

23. Mueller PS, Vester JW, Fermaglich J: Neuroleptic malignant syndrome: successful treatment with bromocriptine. JAMA 249:386-388, 1983 